\title{
Halt hereditary tragedy by bridging the gap between knowledge and application of technology
}

\author{
${ }^{1}$ KK Lau *, FRCP, FHKAM (Medicine), ${ }^{2}$ Ernest Ng, MD, FHKAM (Obstetrics and Gynaecology), ${ }^{3}$ YM Tso, M Phil, ${ }^{4}$ CM Mak, MD, PhD \\ ${ }^{1}$ Department of Medicine and Geriatrics, Princess Margaret Hospital, Laichikok, Hong Kong \\ 2 Department of Obstetrics and Gynaecology, The University of Hong Kong, Queen Mary Hospital, Pokfulam, Hong Kong \\ ${ }^{3}$ Department of Education Studies, Faculty of Social Sciences, Hong Kong Baptist University, Kowloon Tong, Hong Kong \\ ${ }^{4}$ Chemical Pathology \& Genetic Pathology Laboratories, Department of Pathology, Princess Margaret Hospital, Laichikok, Hong Kong \\ Hong Kong Med J 2015;21:188-90 \\ *Corresponding author: dominickklau@hotmail.com \\ DOI: $10.12809 / \mathrm{hkmj} 144464$
}

This article was published on $27 \mathrm{Feb}$ 2015 at www.hkmj.org.
In 1983 , when Hayes ${ }^{1}$ heard on the car radio that a genetic test was available for Huntington's disease, she stopped her car and cried. She recalled her grandfather in a mental hospital with chorea movement and dementia. Her aunt and uncle were later to suffer the same fate. When her mother was diagnosed, she realised that her brother and she were at high risk. Although this hereditary pattern was well recognised, it was never discussed openly. She broke down before the genetic test. ${ }^{1}$

After three decades of research, there have been many breakthroughs in the diagnosis of genetic diseases. In the case of spinocerebellar ataxia (SCA), the majority of affected patients have autosomal dominant inheritance. ${ }^{2,3}$ Today, a genetic test can be performed as early as 3 days following fertilisation during in-vitro fertilisation (IVF). ${ }^{4}$ Preimplantation genetic diagnosis (PGD), which analyses genetic makeup from one biopsied cell of a 3-day-old embryo, allows confirmation of SCA before the embryo is transferred back to the uterus. ${ }^{4}$

Despite these advances, there remains no cure and genetic testing can be a double-edged sword. Early diagnosis is possible but stressful for the sufferer. ${ }^{1,5}$ The impact also affects all blood-related family members and is lifelong.

Although genetic constituents cannot be changed, the problem of acquired hereditary disease can be addressed by selection of unaffected embryos. Assisted reproductive technology (ART) has advanced rapidly since the first IVF baby was delivered in $1978 .^{6}$ Together with PGD, the transmissibility of many hereditary diseases and their management have been transformed. ${ }^{7}$ Assisted reproductive technology is associated with low success rates, risks of ovarian hyperstimulation syndrome and multiple pregnancies, and requires prenatal confirmation. Thus PGD has received great attention and has raised both local and international concern because of varying beliefs and cultures. ${ }^{7}$

The development of ART has entered a new era, with a vivid description in a 2003 UNESCO (United Nations Educational, Scientific and Cultural
Organization) report on PGD and Germ-Line Intervention": "IVF aims at having a child, PGD aims at having a healthy child and PGD/HLA [human leukocyte antigen] testing aims at having a healthy and helpful child." The ethical issues that surround ART have never been underestimated. ${ }^{9}$

There are patients who exhibit full clinical features of hereditary cerebellar ataxia, but the responsible genes have not been identified. ${ }^{10}$ The percentage of familial SCA gene mutations identified is estimated to be $50 \%$ to $80 \%$, with variation due to geographical difference. ${ }^{11}$ Although the number of identifiable SCA genes has expanded, those individuals with no identifiable gene cannot receive a genetic diagnosis, and thus cannot benefit from PGD/ART.

In Hong Kong, there is stigma associated with genetic testing. "Recipients of genetic testing have complained of being rejected by insurance companies." (written communication, YM Tso, Founding Chair of Hong Kong Spinocerebellar Ataxia Association [HKSCAA], 2014). “They are barred from normal medical policies, or the insurance loading will be increased tremendously."

The HKSCAA was established in 2007, and includes SCA patients and their relatives. A survey within HKSCAA was carried out in December 2014. ${ }^{12}$ Study subjects were asymptomatic family members of SCA sufferers, aged between 18 and 50 years. Of the 25 who replied, 22 (88\%) were aware that a genetic test could confirm the diagnosis, and 24 (96\%) knew that they had a $50 \%$ chance of transmitting the condition to any children. It was noteworthy that 13 (52\%) were unaware that ART could help them avoid transmitting SCA to the next generation. There is thus a gap between advances in medical technology and their application. ${ }^{13}$ "For asymptomatic members from SCA family, the need for PGD has to be met. However, PGD is an expensive procedure and should be covered by the public health system as most affected individuals cannot afford it." (written communication, YM Tso, 2014). 
A question about pre-genetic counselling was asked in the same survey. ${ }^{12}$ Of the 25 respondents, 15 (60\%) did not know that pre-testing "psychological preparation" was necessary. ${ }^{13-15}$ They had no concept of being psychologically prepared for both positive or negative result before the test. These individuals have two unfulfilled needs: first, a structured psychological referral that should be easily available, and second, knowledge that this need exists. There is thus a requirement for high-quality psychological support prior to a test that will impact both the person being tested and their relatives. ${ }^{10,15,16}$

The survey did not question individuals about future plans to marry or bear children. It is likely that were such questions asked, respondents might not have known how to answer. A German study revealed that some affected individuals would get pregnant despite the knowledge of $50 \%$ risk of having an affected child. ${ }^{17}$

The opinions and beliefs of partners also deserve consideration, ${ }^{10}$ and whenever possible, both parties should be involved in discussions. ${ }^{15}$ Studies have shown that patients remember subjectively: information is received and processed within their personal frame of reference, or only selectively recalled. ${ }^{18}$

Supporting information, such as pamphlets and websites, are useful. ${ }^{12}$ Ample time should be available at each consultation for questions, and sufficient time allowed between each visit to process information. ${ }^{15}$ Other possibilities such as adoption can also be mentioned. ${ }^{14}$ Studies have shown that women have mixed beliefs about when a baby is formed, or when it is considered a living being. ${ }^{14}$

In some instances, an affected pregnancy is voluntarily terminated following invasive prenatal diagnosis during pregnancy. In a 2010 study in the Netherlands, $42 \%$ of the respondents were not aware of PGD. ${ }^{19}$ Nevertheless when asked if they would welcome the option, only $74 \%$ answered yes. Some couples did not want any diagnostic testing and welcomed the child regardless of whether or not the genetic disorder was present. Whatever the decision, patients' wishes must be respected. ${ }^{19}$

In another study, potential couples with a hereditary disease were found to enter into complex, dynamic, and interactive decision-making processes that could be divided into four phases: identify, contemplate, resolve, and engage. ${ }^{20}$ In the identify phase, couples acknowledged the meaning and their risk. In the contemplate phase, they identified their options in reproduction. In the resolve phase, there were three options: accept, decline, or oscillate. In the engage phase, the final decision was made..$^{20}$

There is a gap between available technology and public knowledge about it. When a person with a family history of SCA wishes to start a family, referral channels that involve an obstetrician, a clinician, and a pathologist with genetic training should be easily accessible for premarital counselling. ${ }^{15}$ The waiting time should not be long. Only health care professionals have the knowledge and capacity to provide the essential support that is required. ${ }^{1,5}$ The issue is sensitive and incurs social, ethical, and legal aspects. ${ }^{9,16}$ Care should be sincere and pragmatic and the referral structure should be timely. ${ }^{1,4}$ Couples should be equipped with sufficient knowledge to make informed choices before they embark on the route to parenthood. ${ }^{19}$

\section{References}

1. Hayes CV. Genetic testing for Huntington's disease-a family issue. N Engl J Med 1992;327:1449-51.

2. Harding AE. Classification of the hereditary ataxias and paraplegias. Lancet 1983;1:1151-5.

3. Lima L, Coutinho P. Clinical criteria for diagnosis of Machado-Joseph disease: report of a non-Azorena Portuguese family. Neurology 1980;30:319-22.

4. Handyside AH, Kontogianni EH, Hardy K, Winston RM. Pregnancies from biopsied human preimplantation embryos sexed by Y-specific DNA amplification. Nature 1990;344:768-70.

5. Wiggins S, Whyte P, Huggins $M$, et al. The psychological consequences of predictive testing for Huntington's disease. Canadian Collaborative Study of Predictive Testing. N Engl J Med 1992;327:1401-5.

6. Steptoe PC, Edwards RG. Birth after the reimplantation of a human embryo. Lancet 1978;2:366.

7. Human Genetics Commission Consultation, Choosing the future: genetics and reproductive decision making. Available from: http://www.geneticalliance.org.uk/docs/ hgcreproduction2004.pdf. Accessed Jan 2015.

8. UNESCO. International Bioethics Committee (IBC): Report of the IBC on pre-implantation genetic diagnosis and germ-line intervention; 2003.

9. Wertz DC, Fletcher JC Berg K. Review of ethical issues in medical genetics. WHO: Geneva; 2003. Available from: http://www.who.int/genomics/publications/en/ethical_ issuesin_medgenetics\%20report.pdf?ua=1. Accessed Jan 2015.

10. Box H, Bonney H, Greenfield J. The patient's journey: the progressive ataxias. BMJ 2005;331:1007-9.

11. Soong BW. Hereditary spinocerebellar ataxias: number, prevalence, and treatment prospects. Hong Kong Med J 2004;10:229-30.

12. 「眼淚可以不再流」醫學講座暨問卷調查結果. “No more tears" - Medical lecture and survey results about cerebellar atrophy [in Chinese]. Available from: http:// www.hkscaa.org/main.php. Accessed 19 Dec 2014.

13. Ethics Committee of American Society for Reproductive Medicine. Use of preimplantation genetic diagnosis for serious adult onset conditions: a committee opinion. Fertil Steril 2013;100:54-7.

14. van Schendel RV, Kleinveld JH, Dondorp WJ, et al. Attitudes of pregnant women and male partners towards non-invasive prenatal testing and widening the scope of prenatal screening. Eur J Hum Genet 2014;22:1345-50.

15. Rantanen E, Hietala M, Kristoffersson U, et al. What is ideal genetic counselling? A survey of current international guidelines. Eur J Hum Genet 2008;16:445-52. 
16. Conti A, Delbon P, Sirignano A. Informed consent when taking genetic decisions. Med Law 2004;23:337-53.

17. Kreuz FR. Attitudes of German persons at risk for Huntington's disease toward predictive and prenatal testing. Genet Couns 1996;7:303-11.

18. Michie S, McDonald V, Marteau TM. Genetic counselling: information given, recall and satisfaction. Patient Educ Couns 1997;32:101-6.
19. Musters AM, Twisk M, Leschot NJ, et al. Perspectives of couples with high risk of transmitting genetic disorders. Fertil Steril 2010;94:1239-43.

20. Hershberger PE, Gallo AM, Kavanaugh K, Olshansky E, Schwartz A, Tur-Kaspa I. The decision-making process of genetically at-risk couples considering preimplantation genetic diagnosis: initial findings from a grounded theory study. Soc Sci Med 2012;74:1536-43. 